Open Access

\title{
Maternal exposure to metals and persistent pollutants and cord blood immune system biomarkers
}

\author{
Jillian Ashley-Martin ${ }^{1}$, Adrian R. Levy ${ }^{2}$, Tye E. Arbuckle ${ }^{3}$, Robert W Platt ${ }^{4}$, Jean S Marshall ${ }^{5}$ and Linda Dodds $6^{6^{*}}$
}

\begin{abstract}
Background: The fetal time period is a critical window of immune system development and resulting heightened susceptibility to the adverse effects of environmental exposures. Epidemiologists and toxicologists have hypothesized that persistent organic pollutants, pesticides and metals have immunotoxic properties. Immunotoxic effects may manifest as an altered immune system profile at birth. Immunoglobulin E, thymic stromal lymphopoietin (TSLP), and interleukin-33 (IL-33) may be implicated in the etiology of childhood allergy and are detectable at birth. The objective of this study was to examine the potential relationship between maternal concentrations of metals, persistent organic pollutants, and pesticides and elevated umbilical cord blood concentrations of IgE, TSLP, and IL-33 in a Canadian birth cohort.
\end{abstract}

Methods: This study utilized data collected in the Maternal-Infant Research on Environmental Chemicals (MIREC) Study, a trans-Canada cohort study of 2,001 pregnant women. Of these women, 1258 had a singleton, term birth and cord blood sample. Logistic regression was used to determine associations between log-transformed continuous variables and immune system biomarkers.

Results: Inverse relationships were observed between lead, DDE, PCB-118, and a summary index of organophosphorous metabolites and jointly elevated concentrations of IL-33 and TSLP. None of the environmental contaminants were associated with increased odds of a high cord blood immune system biomarker concentration.

Conclusions: In this primarily urban Canadian population of pregnant women and their newborns, maternal blood or urine concentrations of persistent organic pollutants, pesticides, and metals were not associated with immunotoxic effects that manifest as increased odds of elevated concentrations of IgE, TSLP or IL-33.

Keywords: Persistent organic pollutants, Metals, Pesticides, Immunoglobulin E, Thymic stromal lymphopoietin, Interleukin-33, Pregnancy, Cohort

\section{Background}

In utero exposures to certain environmental contaminants can trigger permanent, irreversible changes to the developing immune system. These changes may promote the persistence of skewed immune system responses and subsequent increased risk of an allergic phenotype [1-3].

Toxicologists and epidemiologists have hypothesized that metals $[1,4,3]$, pesticides $[5,6]$, and polychlorinated biphenyls (PCBs) $[7,8]$ have immunotoxic properties.

\footnotetext{
*Correspondence: I.dodds@dal.ca

${ }^{6}$ Department of Obstetrics \& Gynaecology and Paediatrics, Dalhousie University, Perinatal Epidemiology Research Unit, 7th Floor Women's Site, IWK Health Centre, 5980 University Ave, PO Box 9700, Halifax, NS B3H 6R8, Canada

Full list of author information is available at the end of the article
}

The majority of North Americans have detectable blood concentrations of metals $[9,10]$. Organophosphate pesticide exposure is common, even in urban populations, due to ingestion of pesticide residues on treated food [11] and presence in household dust [12]. Many adults have detectable concentrations of persistent organic pollutants (POPs), including polychlorinated biphenyls (PCBs) [13] and certain organochlorine pesticides [14] due to their lipophilic and persistent nature [10].

In utero environmental contaminant exposure may be associated with altered levels of immune system biomarkers at birth and possible subsequent risk of childhood allergy $[15,16]$. The immune system biomarkers, immunoglobulin E (IgE), interleukin-33 (IL-33) and thymic 
stromal lymphopoietin (TSLP), have been detected at birth [17] and are integral in the mechanisms underlying allergic responses [18]. Cord blood IgE concentrations have been previously used as a biomarker of the immunotoxic effects of in utero environmental contaminant exposure [19-22]. TSLP and IL-33 have recently been recognized for their etiologic role in atopic dermatitis, the earliest manifestation of childhood allergy [23]. TSLP has also been recently recognized for its role in childhood allergy [24]. Unlike lymphopoietic cell- derived Th2 cytokines, TSLP and IL-33 are produced by epithelial cells and, therefore, not dependent on the presence of a mature immune system [25]. Moreover, epithelial cells have recently been recognized for their role in the regulation of innate and adaptive immune system responses [26, 27]. By lining the digestive, respiratory tract, and skin, epithelial cells may represent the point of entry for environmental contaminant exposure [28].

The objective of the present study was to determine the association between maternal concentrations of pesticides, PCBs, and metals and elevated cord blood concentrations of IgE, TSLP, and IL-33 using data from a Canadian birth cohort. A secondary objective was to assess whether these associations differed by infant sex [29].

\section{Methods}

\section{Study population}

Data and biospecimens were obtained from the MaternalInfant Research on Environmental Chemicals (MIREC) Study, a trans-Canada cohort study of 2,001 pregnant women from ten Canadian cities recruited between 2008 and 2011 [30]. The target population and exclusion criteria for the MIREC study and present analysis have been described previously $[17,30]$. Cord blood samples that were determined to be contaminated with maternal blood based on an elevated immunoglobulin A (IgA) concentration $(\geq 10 \mu \mathrm{g} / \mathrm{mL})$ were excluded from the analysis [31]. As pre-term and multiple birth infants had lower cord blood samples of the immune system biomarkers and may have a differing allergic disease risk profile [32, 33], these samples were excluded. This study received ethical approval from Health Canada, St. Justine's Hospital (Montreal, QC), and the IWK Health Centre (Halifax, NS) and all participants provided consent.

\section{Environmental Contaminant Exposure}

In the present investigation, four organochlorine pesticides, four PCB congeners, five organophosphate pesticide metabolites, and four metals were analyzed. These organochlorine pesticides and PCB congeners were measured in first trimester plasma (Table 1). The non-dioxin like PCB congeners 138,153 , and 180 were summed to create an index of PCB exposure. Plasma samples were analyzed by gas chromatography coupled to a mass spectrometer (Agilent 6890 N/5973 GC-MS). The organophosphate pesticide metabolites were measured in first trimester urine (Table 1). Index measures of the dimethyl alkylphosphate (DMAP) and diethyl alkylphosphate (DEAP) metabolites were calculated by summing the respective metabolites on a molar basis [34]. As only $2 \%$ of samples had detectable concentrations of the organophosphate metabolite DEDTP, this metabolite was not analysed. Organophosphate metabolites in urine were measured with a GC-MS-MS instrument with a GC Agilent6890 N (Agilent Technologies; Mississauga, ON, Canada) coupled with a tandem mass spectrometer Quattro Micro GC (Waters; Milford, Massachusetts, USA).

First and third trimester whole blood metals (lead, mercury, arsenic, and cadmium) concentrations were averaged to create an index of exposure throughout pregnancy. Metal concentrations were analyzed using inductively coupled plasma mass spectrometry (PerkinElmer ELAN ICP-MS DRC II). All chemical analyses of blood and urine samples were carried out at the Toxicology Centre of the Quebec Institute of Public Health, accredited by the Standards Council of Canada.

\section{Fetal Immune System Markers}

Immune system biomarkers were measured in the plasma of umbilical cord blood samples (details in [17]). TSLP concentrations were determined using a commercial antibody kit (Biolegend, San Diego, CA, USA). IL-33 concentrations were analyzed using antibodies from an R \& D systems duoset (Minneapolis, MN, USA). ELISA kits (EBioscience, San Diego, CA, USA) were also used to assess both total IgE and IgA concentrations.

\section{Statistical Analysis}

For the descriptive statistics, urinary concentrations of the organophosphate metabolites were adjusted for specific gravity to account for heterogeneity in urinary dilution according to the following formula $\mathrm{P}_{\mathrm{c}}=\mathrm{P}_{\mathrm{i}}$ $\left[\left(\mathrm{SG}_{\mathrm{m}}-1\right) /\left(\mathrm{SG}_{\mathrm{i}}-1\right)\right]$, where: $P_{c}=\mathrm{SG}$ adjusted metabolite concentration $(\mu \mathrm{g} / \mathrm{ml}), P_{\mathrm{i}}=$ observed metabolite concentration, $S G_{\mathrm{i}}=$ specific gravity of the urine sample, and $\mathrm{SG}_{\mathrm{m}}=$ median SG for the cohort [35].

Due to the high percentage of cord blood samples below the limit of detection (LOD), each immune system biomarker was categorized into a binary variable. A composite variable was developed to identify samples with elevated concentrations of both TSLP and IL-33 (IL-33/TSLP) as these cytokines are highly correlated (Spearman correlation coefficient $=0.8$ ) and known to interact in experimental models [26]. Elevated concentrations of TSLP and IL-33 were defined as samples that exceeded the $80^{\text {th }}$ percentile for both cytokines (TSLP $=$ $554 \mathrm{pg} / \mathrm{mL}$; IL-33 $=879 \mathrm{pg} / \mathrm{mL}$ ) because there are no pre-existing thresholds. Elevated $\mathrm{IgE}$ samples were 
Table 1 Descriptive statistics of environmental contaminants (MIREC study, 2008-2011)

\begin{tabular}{|c|c|c|c|c|c|c|c|}
\hline Chemical $(\mu \mathrm{g} / \mathrm{L})$ & $\mathrm{N}$ & LOD & $\%>L O D$ & Min & Median & Max & IQR \\
\hline \multicolumn{8}{|l|}{ Organochlorine Pesticides (plasma) } \\
\hline Trans-nonachlor & 1232 & 0.01 & 84.58 & LOD & 0.02 & 0.23 & 0.01 \\
\hline p,p'-Dichlorodiphenyldichloroethylene (DDE) & 1233 & 0.09 & 99.19 & LOD & 0.30 & 26.00 & 0.28 \\
\hline Hexachlorobenzene & 1232 & 0.04 & 29.71 & LOD & 0.02 & 0.61 & 0.02 \\
\hline Oxychlordane & 1231 & 0.005 & 92.04 & LOD & 0.01 & 0.13 & 0.01 \\
\hline \multicolumn{8}{|l|}{ Organophosphate Pesticide Metabolites(urine) ${ }^{a}$} \\
\hline Dimethylphosphate (DMP) & 1229 & 1.00 & 79.55 & LOD & 3.25 & 43.33 & 4.44 \\
\hline Dimethylthiphosphate (DMTP) & 1227 & 0.60 & 80.49 & LOD & 3.44 & 141.82 & 7.22 \\
\hline Diethyldithiophosphate (DEDTP) & 1230 & 0.30 & 2.27 & LOD & 0.15 & 4.02 & 0.18 \\
\hline Diethylthiophosphate (DETP) & 1229 & $0.3,0.6$ & 52.92 & LOD & 0.65 & 31.89 & 0.85 \\
\hline Diethylphosphate (DEP) & 1230 & 1.00 & 76.64 & LOD & 2.38 & 2104.76 & 2.90 \\
\hline \multicolumn{8}{|l|}{ Polychlorinated biphenyls (plasma) } \\
\hline PCB 118 & 1233 & 0.01 & 74.45 & LOD & 0.01 & 0.22 & 0.02 \\
\hline PCB 138 & 1233 & 0.01 & 93.19 & LOD & 0.03 & 0.28 & 0.02 \\
\hline PCB 153 & 1233 & 0.01 & 99.19 & LOD & 0.04 & 0.53 & 0.04 \\
\hline PCB 180 & 1233 & 0.01 & 92.70 & LOD & 0.03 & 0.77 & 0.03 \\
\hline \multicolumn{8}{|l|}{ Metals (whole blood) } \\
\hline Lead $(\mu \mathrm{g} / \mathrm{dL})$ & 1241 & 0.10 & 100.00 & 0.17 & 0.62 & 4.14 & 0.41 \\
\hline Cadmium & 1241 & 0.04 & 97.42 & LOD & 0.20 & 5.06 & 0.17 \\
\hline Arsenic & 1241 & 0.22 & 93.63 & LOD & 0.82 & 34.46 & 0.66 \\
\hline Mercury & 1241 & $0.12,0.10$ & 90.57 & LOD & 0.70 & 10.03 & 1.02 \\
\hline
\end{tabular}

adjusted for specific gravity [41]

defined as those that exceeded $1.2 \mathrm{ng} / \mathrm{mL}(0.5 \mathrm{kU} / \mathrm{L})$, a cut-off point previously used in studies of cord blood $\operatorname{IgE}[36,37]$.

Logistic regression was employed to estimate the association between log-transformed continuous variables and elevated concentrations of IgE and IL-33/TSLP with the exception of hexachlorobenzene. Due to the high percentage of samples below the LOD for this chemical, a binary variable categorized at the LOD was created. For all other chemicals, maximum likelihood estimation was used, assuming a log-normal distribution for sample concentrations. This method of accounting for samples with values below the LOD is less prone to bias than substitution methods that use LOD $/ 2$ or LOD $/ \sqrt{ } 2$ [38]. For environmental contaminants with 2 LODs (e.g. mercury, DETP), all values less than the higher LOD were treated as below the limit of detection. For the summary measures of PCBs congeners and organophosphate metabolites, a value was treated as less than the LOD if each of the individual metabolite values were undetectable.

Potential covariates were identified based on previous literature of predictors of the environmental contaminant exposures (organochlorine pesticides [39], organophosphorous pesticides [40], PCBs [41], metals [42-44]) and predictors of the immune system biomarkers [17, 45].
Maternal blood lipid concentrations were included in the organochlorine and PCB models to account for the lipophilic nature of these chemicals and intra-individual heterogeneity in lipids [46]. Maternal urinary specific gravity was included into the organophosphate pesticide metabolite models to account for heterogeneity in urinary dilution [47]. Maternal age was a priori entered into all models; no predictors of both exposure and outcome were identified. The linearity of the relationship between each environmental contaminant and immune system biomarker was assessed using restricted cubic splines [48]. To assess whether relationships differed by infant sex, the P-value of the sex*exposure interaction term was assessed and sexstratified analyses were conducted. For statistically significant associations, two additional analyses were conducted using; i) tertiles of exposure and ii) a doubling of exposure concentrations. This was done for ease of interpretation and visualization of results. A linear test for trend was performed to evaluate dose-response relationships between tertiles of exposure and the immune system biomarker of interest; resulting P-values were reported.

\section{Results}

Of the 2,001 women recruited, 18 withdrew and asked that all their data and biospecimens be destroyed. Of the 
remaining 1,983 subjects, 1,363 women had a cord blood sample. Of these 1,363 samples, 107 were excluded for missing chemical exposure data, a high IgA concentration, pre-term birth ( $<37$ weeks), multiple birth, or samples with insufficient sample for analysis. Among the eligible subset of study participants (term, singleton births), there were no notable differences between women with and without a cord blood sample in regard to parental smoking, maternal age, or BMI. Seventy-three percent of the eligible participants in the cohort had a cord blood sample that was included in the analytical sample.

Table 1 shows descriptive statistics of the environmental contaminants. The percentage of samples above the limit of detection ranged from $29.7 \%$ for hexachlorobenzene to $100 \%$ for lead. Maternal demographic, reproductive, and infant characteristics are depicted in Table 2. The majority of study participants were 30 years or older, had a household income greater than $\$ 50,000$, were non-smokers, and of normal BMI.

As no chemical met the criteria for non-linearity, all exposures were entered into the model as continuous variables without a quadratic term. Results of the IL-33/TSLP and IgE models are presented in Tables 3 and 4 respectively. All models were adjusted for age and, depending on the specific chemical, specific gravity or lipids. Significant inverse associations were observed between maternal lead concentrations, DDE concentrations, PCB 118 concentrations, $\Sigma$ DEP and DETP concentrations and elevated concentrations of IL-33/TSLP (lead aOR $=0.7095 \%$ CI: 0.480.94; DDE aOR $=0.8195 \%$ CI: 0.63-0.98; PCB $118 \mathrm{aOR}=$ $0.6995 \%$ CI: 0.40-0.98; $\Sigma$ DEP and DETP aOR $=0.8595 \%$ CI: 0.72-0.97). No significant associations were observed between any of the environmental contaminants and elevated cord blood concentrations of IgE. There was no observed effect modification by sex or material differences in the sex-stratified analysis (data not shown).

Table 5 depicts the results of the tertile analysis for chemicals with significant associations in the analyses using continuous exposures. Results were consistent with the analysis of continuous exposures though none of the effect measures achieved statistical significance. A suggestion of an inverse finding was observed in the relationship between both DDE and PCB 118 and IL-33/TSLP (P-value test for trend $=0.06$ for both contaminants). A two fold increase in log maternal lead, PCB 118, DDE and $\Sigma D E P$ and DETP concentrations was associated with odds ratios comparable to the analysis using continuous exposures and tertiles (lead aOR $=0.8095 \%$ CI:0.63-1.00; DDE aOR $=0.86$ 95 \% CI:0.74-1.00; PCB 118 aOR = 0.7895 \% CI:0.58-1.03; $\Sigma$ DEP and DETP aOR $=0.9195 \%$ CI: 0.80-1.04).

\section{Discussion}

In this study, we sought to characterize the association between prenatal exposure to PCBs, pesticides and metals
Table 2 Study participant characteristics, MIREC Study, Canada, 2008-2011 $(n=1256)^{a}$

\begin{tabular}{|c|c|c|}
\hline Characteristic & $\mathrm{N}$ & $\%$ \\
\hline \multicolumn{3}{|l|}{ Maternal Demographic } \\
\hline \multicolumn{3}{|l|}{ Maternal Age (yrs.) } \\
\hline$\leq 24$ & 60 & 4.8 \\
\hline $25-29$ & 270 & 21.5 \\
\hline $30-34$ & 450 & 35.8 \\
\hline$\geq 35$ & 476 & 37.9 \\
\hline \multicolumn{3}{|l|}{ Household Income (\$CAD) } \\
\hline$\leq 30,000$ & 90 & 7.5 \\
\hline $30,001-50,000$ & 116 & 9.6 \\
\hline $50,001-100,000$ & 514 & 42.6 \\
\hline$>100,000$ & 487 & 40.4 \\
\hline \multicolumn{3}{|l|}{ Parental Smoking ${ }^{b}$} \\
\hline No & 1006 & 80.1 \\
\hline Yes & 250 & 19.9 \\
\hline \multicolumn{3}{|l|}{ Pet Ownership } \\
\hline No & 559 & 44.5 \\
\hline Yes & 697 & 55.5 \\
\hline \multicolumn{3}{|c|}{ Maternal Reproductive \& Medical History } \\
\hline \multicolumn{3}{|l|}{ Pre-Pregnancy BMI ${ }^{\mathrm{C}}$} \\
\hline Underweight $(<18.5)$ & 27 & 2.3 \\
\hline Normal (18.5 to 24.9 ) & 717 & 60.5 \\
\hline Overweight (25 to 29.9 ) & 272 & 22.9 \\
\hline Obese $(\geq 30)$ & 170 & 14.3 \\
\hline \multicolumn{3}{|l|}{ Maternal Allergy ${ }^{d}$} \\
\hline No & 1202 & 95.7 \\
\hline Yes & 54 & 4.3 \\
\hline \multicolumn{3}{|l|}{ Parity } \\
\hline Nulliparous & 526 & 41.9 \\
\hline Primiparous & 512 & 40.8 \\
\hline \multirow[t]{2}{*}{ Multiparous } & 216 & 17.2 \\
\hline & 2 & \\
\hline
\end{tabular}

Infant Characteristics

Infant Sex

$\begin{array}{lll}\text { Male } & 671 & 53.5\end{array}$

$\begin{array}{lll}\text { Female } & 584 & 46.5\end{array}$

Birth Weight (g)

$\begin{array}{lll}<2500 & 11 & 0.9\end{array}$

$2500-<3500 \quad 606 \quad 48.2$

$3500-<4000 \quad 448 \quad 35.7$

\begin{tabular}{lll}
$\geq 4000$ & 192 & 15.3 \\
\hline
\end{tabular}

aSubtotals may not sum to total due to missing data, ${ }^{b}$ defined as either the mother or father smoking during pregnancy, 'World Health Organization Classification [66], ${ }^{\mathrm{d}}$ Defined as maternal use of allergy medication 
Table 3 Odds ratio of $\log _{10}$ maternal contaminant concentrations and elevated ( $\geq 80 \%$ ) cord blood concentrations of IL-33/TSLP

\begin{tabular}{|c|c|c|c|}
\hline Chemical $(\mu \mathrm{g} / \mathrm{L})$ & $N$ & $\begin{array}{l}\text { Unadjusted OR } \\
\text { (95\% Cl) }\end{array}$ & $\begin{array}{l}\text { Adjusted OR } \\
(95 \% \mathrm{Cl})\end{array}$ \\
\hline \multicolumn{4}{|l|}{ Organochlorine Pesticides $^{\text {a }}$} \\
\hline Trans-nonachlor & 1232 & $0.83(0.61-1.07)$ & $0.77(0.46-1.08)$ \\
\hline DDE & 1233 & $0.80(0.64-0.97)$ & $0.81(0.63-0.98)$ \\
\hline $\begin{array}{l}\text { Hexachlorobenzene } \\
\text { (binary) }\end{array}$ & 1232 & $0.79(0.56-1.10)$ & $0.79(0.56-1.14)$ \\
\hline Oxychlordane & 1231 & $0.84(0.61-1.07)$ & $0.80(0.49-1.10)$ \\
\hline \multicolumn{4}{|l|}{$\begin{array}{l}\text { Organophosphate Pesticide } \\
\text { Metabolites }^{b}\end{array}$} \\
\hline $\begin{array}{l}\text { Dimethylphosphate } \\
\text { (DMP) }\end{array}$ & 1229 & $0.86(0.75-0.97)$ & $0.85(0.68-1.02)$ \\
\hline $\begin{array}{l}\text { Dimethylthiphosphate } \\
\text { (DMTP) }\end{array}$ & 1227 & $0.99(0.89-1.08)$ & $0.98(0.84-1.12)$ \\
\hline $\begin{array}{l}\text { Diethylthiophosphate } \\
\text { (DETP) }\end{array}$ & 1229 & $0.95(0.81-1.09)$ & $0.96(0.72-1.22)$ \\
\hline Diethylphosphate (DEP) & 1230 & $0.85(0.73-0.97)$ & $0.87(0.67-1.06)$ \\
\hline$\Sigma$ DMP\&DMTP & 1226 & $0.90(0.79-1.02)$ & $0.91(0.80-1.03)$ \\
\hline$\Sigma$ DEP\&DETP & 1229 & $0.85(0.72-0.98)$ & $0.85(0.72-0.97)$ \\
\hline \multicolumn{4}{|l|}{ Polychlorinated biphenyls ${ }^{a}$} \\
\hline PCB 118 & 1233 & $0.83(0.62-1.05)$ & $0.69(0.40-0.98)$ \\
\hline PCB 138 & 1233 & $0.85(0.67-1.05)$ & $0.86(0.62-1.10)$ \\
\hline PCB 153 & 1233 & $0.87(0.68-1.06)$ & $0.86(0.65-1.08)$ \\
\hline PCB 180 & 1233 & $0.87(0.70-1.04)$ & $0.95(0.72-1.19)$ \\
\hline $\begin{array}{l}\sum \mathrm{PCB} \text { (non-dioxin - } \\
138,153,180 \text { ) }\end{array}$ & 1233 & $0.87(0.68-1.07)$ & $0.89(0.67-1.11)$ \\
\hline \multicolumn{4}{|l|}{ Metals ${ }^{\mathbf{c}}$} \\
\hline Lead & 1241 & $0.70(0.48-0.94)$ & $0.72(0.48-0.95)$ \\
\hline Cadmium & 1241 & $0.91(0.73-1.10)$ & $0.92(0.73-1.11)$ \\
\hline Arsenic & 1241 & $0.94(0.73-1.14)$ & $0.95(0.73-1.17)$ \\
\hline Mercury & 1241 & $0.94(0.80-1.07)$ & $0.96(0.82-1.10)$ \\
\hline
\end{tabular}

and elevated concentrations of IgE, IL-33 and TSLP. We observed inverse associations between maternal lead, $\mathrm{PCB}$ 118, DDE, EDEP and DETP and IL-33/TSLP. No effect modification by sex was observed in these relationships. Our findings suggest that contemporary maternal concentrations of these environmental contaminants are not associated with developmental immunotoxicity as measured by the immune system biomarkers of interest.

Experimental evidence has demonstrated that gestational lead exposure may elevate IgE concentrations [3, 49] and enhance Th2 cell responses [50]. A significantly elevated risk of childhood atopy was observed among children with elevated maternal and cord blood lead concentrations in a Polish birth cohort [51]. Significant correlations between childhood lead concentrations and
Table 4 Odds ratio of $\log _{10}$ maternal contaminant concentrations and elevated ( $\geq 0.5 \mathrm{ku} / \mathrm{L}$ ) cord blood concentrations of IgE

\begin{tabular}{|c|c|c|c|}
\hline Chemical $(\mu \mathrm{g} / \mathrm{L})$ & $\mathrm{N}$ & $\begin{array}{l}\text { Unadjusted OR } \\
(95 \% \mathrm{Cl})\end{array}$ & $\begin{array}{l}\text { Adjusted OR } \\
(95 \% \mathrm{Cl})\end{array}$ \\
\hline \multicolumn{4}{|l|}{ Pesticides } \\
\hline \multicolumn{4}{|l|}{ Organochlorine Pesticides ${ }^{\mathrm{a}}$} \\
\hline Trans-nonachlor & 1232 & $0.81(0.59-1.03)$ & $0.86(0.51-1.10)$ \\
\hline DDE & 1233 & $0.93(0.75-1.12)$ & $1.00(0.79-1.20)$ \\
\hline $\begin{array}{l}\text { Hexachlorobenzene } \\
\text { (binary) }\end{array}$ & 1232 & $0.87(0.62-1.20)$ & $0.89(0.62-1.27)$ \\
\hline Oxychlordane & 1231 & $0.84(0.61-1.07)$ & $1.01(0.62-1.40)$ \\
\hline \multicolumn{4}{|l|}{$\begin{array}{l}\text { Organophosphate Pesticide } \\
\text { Metabolites }{ }^{b}\end{array}$} \\
\hline $\begin{array}{l}\text { Dimethylphosphate } \\
\text { (DMP) }\end{array}$ & 1229 & $0.97(0.85-1.10)$ & $1.01(0.81-1.21)$ \\
\hline Diethylphosphate (DEP) & 1230 & $0.91(0.78-1.04)$ & $0.88(0.69-1.08)$ \\
\hline $\begin{array}{l}\text { Dimethylthiphosphate } \\
\text { (DMTP) }\end{array}$ & 1227 & $0.98(0.88-1.07)$ & $0.92(0.79-1.06)$ \\
\hline $\begin{array}{l}\text { Diethylthiophosphate } \\
\text { (DETP) }\end{array}$ & 1229 & $0.99(0.84-1.13)$ & $0.95(0.70-1.19)$ \\
\hline ¿DMP\&DMTP & 1226 & $0.96(0.84-1.08)$ & $1.00(0.81-1.11)$ \\
\hline ¿DEP\&DETP & 1229 & $0.95(0.81-1.09)$ & $0.86(0.70-1.01)$ \\
\hline \multicolumn{4}{|l|}{ Polychlorinated biphenyls ${ }^{a}$} \\
\hline PCB 118 & 1233 & $0.98(0.74-1.23)$ & $1.08(0.68-1.49)$ \\
\hline PCB 138 & 1233 & $0.96(0.75-1.17)$ & $1.11(0.81-1.40)$ \\
\hline PCB 153 & 1233 & $0.96(0.76-1.17)$ & $1.08(0.82-1.33)$ \\
\hline PCB 180 & 1233 & $0.93(0.75-1.11)$ & $1.07(0.82-1.33)$ \\
\hline $\begin{array}{l}\sum P C B(\text { non-dioxin - } \\
138,153,180)\end{array}$ & 1233 & $0.95(0.74-1.16)$ & $1.07(0.81-1.33)$ \\
\hline \multicolumn{4}{|l|}{ Metals ${ }^{c}$} \\
\hline Lead & 1241 & $0.92(0.63-1.23)$ & $0.98(0.66-1.30)$ \\
\hline Cadmium & 1241 & $0.90(0.72-1.09)$ & $0.91(0.73-1.10)$ \\
\hline Arsenic & 1241 & $1.16(0.90-1.41)$ & $1.20(0.93-1.47)$ \\
\hline Mercury & 1241 & $0.95(0.81-1.09)$ & $1.00(0.84-1.15)$ \\
\hline
\end{tabular}

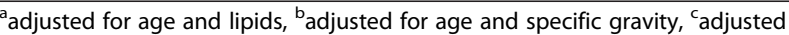
for age

both elevated IgE [52-54] and atopic dermatitis [55] have been identified in cross-sectional analyses. In light of these previous findings, the observed lack of association between lead and IgE an inverse association between lead and IL-33/TSLP in the present study was unexpected.

There is experimental evidence that PCBs may enhance production of Th2 cell cytokines involved in allergic responses [8]. Similar associations have not, however, been consistently observed in epidemiologic studies. For example, a meta-analysis of ten European cohort studies concluded that prenatal PCB-153 exposure was not associated with infant wheeze or bronchitis [56]. Conversely, authors of a recent Dutch cohort study reported a positive association between prenatal PCB-153 
Table 5 Odds ratios of tertiles of exposure and elevated ( $\geq 80 \%)$ cord blood concentrations of IL-33/TSLP for contaminants shown to have significant associations from Table 2

\begin{tabular}{|c|c|c|}
\hline Contaminant & Tertiles & Adjusted OR (95\% Cl) \\
\hline$\overline{D^{\prime} E^{a}(u g / L)}$ & $\leq 0.23$ & 1.0 \\
\hline \multirow[t]{2}{*}{$(n=1233)$} & $0.24-0.39$ & $0.75(0.51-1.09)$ \\
\hline & $>0.39$ & $0.69(0.47-1.02)$ \\
\hline P-value test for trend & & 0.06 \\
\hline PCB $118^{\mathrm{a}}(\mathrm{ug} / \mathrm{L})$ & $\leq 0.011$ & 1.0 \\
\hline \multirow[t]{2}{*}{$(n=1233)$} & $0.011-0.018$ & $0.85(0.58-1.23)$ \\
\hline & $>0.018$ & $0.67(0.45-1.02)$ \\
\hline P-value test for trend & & 0.06 \\
\hline$\Sigma$ DEP\&DETPb ${ }^{\mathrm{b}}(\mathrm{ug} / \mathrm{L})$ & $\leq 12.60$ & 1.0 \\
\hline \multirow[t]{2}{*}{$(n=1229)$} & $12.61-26.90$ & $0.84(0.57-1.24)$ \\
\hline & $>26.90$ & $0.89(0.56-1.40)$ \\
\hline P-value test for trend & & 0.08 \\
\hline Lead $^{c}(\mathrm{ug} / \mathrm{dL})$ & $\leq 0.68$ & 1.0 \\
\hline \multirow[t]{2}{*}{$(n=1241)$} & $0.69-1.08$ & $0.83(0.57-1.20)$ \\
\hline & $>1.08$ & $0.77(0.53-1.11)$ \\
\hline P-value test for trend & & 0.16 \\
\hline
\end{tabular}

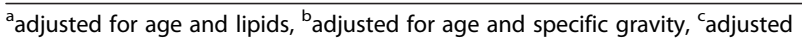
for age

exposure and self-reported asthma medication use between the ages of 6 and 20 [57].

Experimental evidence has also demonstrated that organochlorine pesticide exposure, specifically DDE, may also induce allergic type responses via enhanced production of Th2 cytokines [6]. Though positive associations between prenatal DDE exposure and measures of childhood allergic disease have been reported in two birth cohort studies [58, 59], a meta-analysis of 10 cohort studies reported that this association was limited to children less than 18 months old [56]. In addition, authors of the Dutch cohort study reported no significant association between prenatal DDE exposure $($ median $=2.47 \mathrm{ng} / \mathrm{mL})$ and asthma medication use [57]. While organophosphorous pesticides may alter immune system function [6], we did not identify any birth cohort studies of maternal organophosphorous pesticides exposures and childhood allergic outcomes.

In light of this literature, two primary factors may explain the present findings. First, compared to historical cohorts [51, 57], maternal environmental contaminant concentrations in the MIREC study are relatively low. Average lead concentrations in the MIREC study (geometric mean $=0.88 \mu \mathrm{g} / \mathrm{dL}$ ) were lower than observed in the Polish birth cohort (geometric mean $=1.60 \mu \mathrm{g} / \mathrm{dL}$ ) [51] and notably lower than 1 to $2 \mathrm{ug} / \mathrm{dL}$, values which have been reported to be associated with adverse health effects [60]. Maternal concentrations of PCB-153 and DDE were also lower among MIREC participants than in the Dutch cohort study $($ PCB-153 median $=1.37 \mu \mathrm{g} / \mathrm{L}, \mathrm{DDE}$ median $=0.3 \mu \mathrm{g} / \mathrm{L}$ ) [57]. Second, it possible that the observed inverse associations may be a product of live birth bias [61]. Fetuses that were most susceptible to the toxic effects of contaminant exposure may not have survived until birth. The term fetuses in the present analysis may, therefore, represent a 'healthy' subset of the total number of pregnancies among MIREC study participants.

Our study was also subject to the following four limitations. First, although the persistent organic pollutants and metals have long half-lives and, therefore, little expected variation throughout pregnancy, the organophosphorous metabolites have relatively short half-lives [62] and may vary during pregnancy [63]. Furthermore, first trimester urinary measures may not be representative of exposure during critical windows of immune system development. Considering that 1 ) that exposure misclassification is nondifferential and 2) this study employed continuous rather than polytomous exposure variables, any potential misclassification bias likely attenuated effect estimates towards the null [64]. Second, due to the limited literature regarding IL-33 and TSLP at birth, our choice of cut-off points was not based on clinical guidelines. Rather, we based this cut-off on our previous analysis of predictors of elevated concentrations of IL-33 and TSLP at birth [17]. In the present analysis, we conducted a sensitivity analysis for chemicals with statistically significant associations by dichotomizing IL-33 and TSLP at the limit of detection. As we observed similar odds ratios when using the limit of detection cut-off, we have only reported results using the $80^{\text {th }}$ percentile cut-off. Third, as we did not have clinical data on asthma development in the children, it is not possible to determine the clinical implications of our findings. Fourth, the present results may be subject to negative confounding by an unmeasured protective factor for allergy, such as maternal vitamin D [65].

Despite these limitations, this study benefited from the relatively large sample size and the comparatively rich covariate data. Considering the relatively long-half life for the persistent organic pollutants, there is unlikely to be considerable within-person variability in exposure throughout pregnancy. The value of the present research will become most evident when combined with follow-up studies of MIREC participants into childhood. In conjunction with such follow-up, this research will help determine the timing of any potential immunotoxic effect of in utero exposures and may, ultimately, strengthen understanding of the developmental origins of childhood allergy. This information is relevant to identifying critical windows of exposure and ultimately, to developing public health messages regarding minimizing environmental contaminant exposure.

\section{Conclusions}

In this primarily urban Canadian population of pregnant women and their newborns, maternal concentrations of 
persistent organic pollutants, pesticides, and metals were not associated with elevated IgE, TSLP or IL-33. Generalization of these findings beyond the MIREC study population would require examination in a population of differing socioeconomic status, ethnicity, or health profiles (e.g. smoking and obesity rates). Future studies that examine the trajectory of these biomarkers from birth to childhood will complement the present findings.

\begin{abstract}
Abbreviations
CV: coefficient of variation; DDE: p,p'-Dichlorodiphenyldichloroethylene; DEAP: diethyl alkylphosphate; DEDTP: diethyldithiophophate;

DEP: diethylphosphate; DMAP: dimethyl alkylphosphate;

DETP: diethylthiophosphate; DETP: diethylthiophosphate;

DMP: Dimethylphosphate; DMTP: dimethylthiphosphate; ELISA: enzyme linked immunoassay; IgA: immunoglobulin A; IgE: immunoglobulin E; IL-33: interleukin-33; LOD: limit of detection; MIREC: Maternal-Infant Research on Environmental Chemicals; PCB: polychlorinated biphenyl; POP: persistent organic pollutant; SG: specific gravity; Th2: T helper 2; TSLP: thymic stromal lymphopoietin.
\end{abstract}

\section{Competing interests}

The authors declare that they have no competing interests.

\section{Author contributions}

JAM performed the ELISA analysis of umbilical cord blood samples, conducted the statistical analysis, and wrote the manuscript. LD provided supervisory input regarding the cohort, statistical analysis and critical feedback on the manuscript. ARL assisted in structuring and writing the manuscript. RWP provided guidance on the maximum likelihood modeling and reviewed the statistical methods. JSM provided lab space, materials, and technical support to facilitate the completion of the ELISA analysis and critically reviewed early versions of the manuscript. TEA, co-principal investigator of the MIREC study, provided guidance on the study cohort as well as reviewed and edited the manuscript. All authors were involved with the study design and methodology.

\section{Acknowledgements}

We would like to acknowledge the valuable contributions of Yisong Wei, Nong $\mathrm{Xu}$ (and other members of the Marshall lab) for their assistance in the analysis of the cord blood samples. We would also like to acknowledge the MIREC biobank committee for granting access to the cord blood samples as well as the MIREC study participants for their dedication. This work was funded by a Category A grant (grant \#10012) from the Izaak Walton Killam (IWK) Health Centre. The MIREC Study was funded by the Chemicals Management Plan of Health Canada, the Canadian Institutes for Health Research (grant\# MOP - 81285), and the Ontario Ministry of the Environment.

\section{Author details}

${ }^{1}$ Interdisciplinary PhD Program, Dalhousie University, IDPhD c/o Faculty of Graduate Studies Room 314 Henry Hicks Building 6299 South St Halifax, Halifax, NS B3H 4H6, Canada. ²Department of Community Health \& Epidemiology, Dalhousie University, Centre for Clinical Research, 5790 University Avenue, Halifax, NS B3H 1 V7, Canada. ${ }^{3}$ Population Studies Division, Healthy Environments and Consumer Safety Branch, Health Canada, 50 Colombine Dr., AL 0801A, Ottawa, ON K1A 0 K9, Canada. ${ }^{4}$ Department of Epidemiology and Biostatistics, McGill University, Purvis Hall 1020 Pine Ave. West, Montreal H3A 1A2QC, Canada. ${ }^{5}$ Department of Microbiology \& Immunology, Dalhousie University Sir Charles Tupper Medical Building, Room 7-C5850 College Street, Halifax, NS, Canada. ${ }^{6}$ Department of Obstetrics \& Gynaecology and Paediatrics, Dalhousie University, Perinatal Epidemiology Research Unit, 7th Floor Women's Site, IWK Health Centre, 5980 University Ave, PO Box 9700, Halifax, NS B3H 6R8, Canada.

Received: 2 April 2015 Accepted: 8 June 2015

Published online: 18 June 2015

\section{References}

1. Luebke RW, Chen DH, Dietert R, Yang Y, King M, Luster MI. The comparative immunotoxicity of five selected compounds following developmental or adult exposure. J Toxicol Env Heal Part B. 2006;9:1-26.

2. Holladay S, Smialowicz R. Development of the murine and human immune system: differential effects of immunotoxicants depend on time of exposure. Environ Health Perspect. 2000;108:463-73.

3. Dietert RR, Lee J-E, Hussain I, Piepenbrink M. Developmental immunotoxicology of lead. Toxicol Appl Pharmacol. 2004;198:86-94.

4. Klaasen C. Casarett and Doull's Essentials of Toxicology. 2nd ed. New York: McGraw-Hill Medical; 2010.

5. Vine MF, Stein L, Weigle K, Schroeder J, Degnan D, Tse CJ, et al. Plasma 1, 1-Dichloro-2,2-bis(p-chlorophenyl)ethylene (DDE) levels and immune response. Am J Epidemiol. 2001;153:53-63.

6. Corsini E, Sokooti M, Galli CL, Moretto A, Colosio C. Pesticide induced immunotoxicity in humans: A comprehensive review of the existing evidence. Toxicology. 2013;307:123-35.

7. Hertz-Picciotto I, Park H-Y, Dostal M, Kocan A, Trnovec T, Sram R. Prenatal exposures to persistent and non-persistent organic compounds and effects on immune system development. Basic Clin Pharmacol Toxicol. 2008;102:146-54

8. Gaspar-Ramírez O, Pérez-Vázquez FJ, Pruneda-Álvarez LG, Orta-García ST, González-amaro R, Pérez-Maldonado IN. Effect of polychlorinated biphenyls 118 and 153 on Th1 / Th2 cells differentiation. Immunopharmacol Immunotoxicol. 2012;34:627-32.

9. Statistics Canada. Canadian Health Measures Survey: Cycle 2 Data Tables 2009 to 2011. 2013. http://www.statcan.gc.ca/pub/82-626-x/2013001/t060eng.pdf. Accessed 6 May 2015.

10. NHANES. Fourth national report on human exposure to environmental chemicals. 2013. http://www.cdc.gov/exposurereport/pdf/FourthReport_ UpdatedTables_Sep2013.pdf. Accessed 6 May 2015.

11. Lu C, Barr DB, Pearson MA, Waller LA. Dietary intake and its contribution to longitudinal organophosphorus pesticide exposure in urban/suburban children. Environ Health Perspect. 2008;116:537-42.

12. Stout DM, Bradham KD, Egeghy PP, Jones P, Croghan CW, Ashley P, et al. American Healthy Homes Survey: a national study of residential pesticides measured from floor wipes. Environ Sci Technol. 2009:43:4294-300.

13. Dyke PH, Foan C, Fiedler H. PCB and PAH releases from power stations and waste incineration processes in the UK. Chemosphere. 2003;50:469-80.

14. US Department of Health and Human Services. Toxicological profile for DDT, DDE, and DDD. 2002. http://www.atsdr.cdc.gov/toxprofiles/tp35.pdf. Accessed 6 May 2015.

15. Prescott SL, Clifton V. Asthma and pregnancy: emerging evidence of epigenetic interactions in utero. Curr Opin Allergy Clin Immunol. 2009;9:417-26.

16. Sugiyama M, Arakawa H, Ozawa K, Mizuno T, Mochizuki H, Tokuyama K, et al. Early-life risk factors for occurrence of atopic dermatitis during the first year. Pediatrics. 2007;119:e716-23.

17. Ashley-Martin J, Dodds L, Arbuckle T, Levy A, Platt R, Marshall J. Umbilical cord blood levels and predictors of Interleukin-33, Thymic Stromal Lymphopoietin and Immunoglobulin E. Pediatr Allergy Immunol. 2015;26:161-7.

18. Bartemes KR, Kita H. Dynamic role of epithelium-derived cytokines in asthma. Clin Immunol. 2012;143:222-35.

19. Okada E, Sasaki S, Saijo Y, Washino N, Miyashita C, Kobayashi S, et al. Prenatal exposure to perfluorinated chemicals and relationship with allergies and infectious diseases in infants. Environ Res. 2012;112:118-25.

20. Herr CEW, Ghosh R, Dostal M, Skokanova V, Ashwood P, Lipsett M, et al. Exposure to air pollution in critical prenatal time windows and lgE levels in newborns. Pediatr Allergy Immunol. 2011;22:75-84

21. Wang I-J, Hsieh W-S, Chen C-Y, Fletcher T, Lien G-W, Chiang H-L, et al. The effect of prenatal perfluorinated chemicals exposures on pediatric atopy. Environ Res. 2011;111:785-91.

22. Grandjean P, Poulsen LK, Heilmann C, Steuerwald U, Weihe P. Allergy and sensitization during childhood associated with prenatal and lactational exposure to marine pollutants. Environ Health Perspect. 2010;118:1429-33.

23. Brandt EB, Sivaprasad U. Th2 Cytokines and Atopic Dermatitis. J Clin Cell Imunol. 2011;2:1-25.

24. Gauvreau GM, O’Byrne PM, Boulet L-P, Wang Y, Cockcroft D, Bigler J, et al. Effects of an anti-TSLP antibody on allergen-induced asthmatic responses. New Engl J Med. 2014;370:2102-10. 
25. Brugman S, Perdijk O, van Neerven RJJ, Savelkoul HFJ. Mucosal Immune Development in Early Life: Setting the Stage. Arch Immunol Ther Exp. 2015; doi:10.1007/s00005-015-0329-y.

26. Saenz SA, Taylor BC, Artis D. Welcome to the neighborhood: epithelial cell-derived cytokines license innate and adaptive immune responses at mucosal sites. Immunol Rev. 2009;226:172-90.

27. Proud D, Leigh R. Epithelial cells and airway diseases. Immunol Rev. 2011;242:186-204.

28. Abbas A. Cellular and molecular immunology. Philadelphia, PA: Elsevier Saunders; 2015

29. Kynyk J, Mastronarde JG, McCallister JW. Asthma, the sex difference. Curr Opin Pulm Med. 2011;17:6-11.

30. Arbuckle T, Fraser W, Fisher M, Davis K, Liang C, Lupien N, et al. Cohort Profile: The Maternal-Infant Research on Environmental Chemicals Research Platform. Paediatr Perinat Epidemiol. 2013;27:415-25.

31. Ownby DR, McCullough J, Johnson CC, Peterson EL. Evaluation of IgA measurements as a method for detecting maternal blood contamination of cord blood samples. Pediatr Allergy Immunol. 1996;7:125-9.

32. Been JV, Lugtenberg MJ, Smets E, van Schayck CP, Kramer BW, Mommers M, et al. Preterm birth and childhood wheezing disorders: a systematic review and meta-analysis. PLoS Med. 2014;11:1-19.

33. Algert CS, Bowen JR, Lain SL, Allen HD, Vivian-Taylor JM, Roberts CL. Pregnancy exposures and risk of childhood asthma admission in a population birth cohort. Pediatr Allergy Immunol. 2011;22:836-42.

34. Arcury TA, Grzywacz ÃJG, Davis SW, Barr DB, Quandt SA. Organophosphorus Pesticide urinary metabolite levels of children in farmworker households in Eastern North Carolina. Am J Ind Med. 2006:49:751-60.

35. Just AC, Adibi JJ, Rundle AG, Calafat AM, Camann DE, Hauser R, et al. Urinary and air phthalate concentrations and self-reported use of personal care products among minority pregnant women in New York city. J Expo Sci Env Epidemiol. 2010;20:625-33.

36. Sadeghnejad A, Karmaus W, Davis S, Kurukulaaratchy R, Matthews S, Arshad S. Raised cord serum immunoglobulin E increases the risk of allergic sensitisation at ages 4 and 10 and asthma at age 10. Thorax. 2004;59:936-42.

37. Pesonen M, Kallio MJT, Siimes MA, Elg P, Björksten F, Ranki A. Cord serum immunoglobulin $E$ as a risk factor for allergic symptoms and sensitization in children and young adults. Pediatr Allergy Immunol. 2009;20:12-8.

38. Cole SR, Chu H, Nie L, Schisterman EF. Estimating the odds ratio when exposure has a limit of detection. Int J Epidemiol. 2009;38:1674-80.

39. Wolff MS, Deych E, Ojo F, Berkowitz GS. Predictors of organochlorines in New York City pregnant women, 1998-2001. Environ Res. 2005;97:170-7.

40. Bradman A, Castorina R, Barr DB, Chevrier J, Harnly ME, Eisen EA, et al. Determinants of organophosphorus pesticide urinary metabolite levels in young children living in an agricultural community. Int J Env Res Public Heal. 2011;8:1061-83.

41. Rylander C, Lund E, Frøyland L, Sandanger TM. Predictors of PCP, OH-PCBs, PCBs and chlorinated pesticides in a general female Norwegian population. Environ Int. 2012;43:13-20.

42. Callan A, Hinwood A, Ramalingam M, Boyce M, Heyworth J, McCafferty P, et al. Maternal exposure to metals-concentrations and predictors of exposure. Environ Res. 2013;126:111-7.

43. Taylor CM, Golding J, Hibbeln J, Emond AM. Environmental factors predicting blood lead levels in pregnant women in the UK: the ALSPAC study. PLoS One. 2013;8:1-8.

44. Razzaghi H, Tinker SC, Crider K. Blood mercury concentrations in pregnant and nonpregnant women in the United States: National Health and Nutrition Examination Survey 1999-2006. Am J Obs Gynecol. 2014;210:357.e1-9.

45. Scirica CV, Gold DR, Ryan L, Abulkerim H, Celedón JC, Platts-Mills TA E, et al. Predictors of cord blood IgE levels in children at risk for asthma and atopy. J Allergy Clin Immunol. 2007;119:81-8.

46. Schisterman EF, Whitcomb BW, Buck Louis GM, Louis TA. Lipid Adjustment in the Analysis of Environmental Contaminants and Human Health Risks. Environ Health Perspect. 2005;113:853-7.

47. Arbuckle TE, Davis K, Marro L, Fisher M, Legrand M, Leblanc A, et al. Phthalate and bisphenol A exposure among pregnant women in Canada - Results from the MIREC study. Environ Int. 2014;68C:55-65.

48. Desquilbet $L$, Mariotti F. Dose-response analyses using restricted cubic spline functions in public health research. Stat Med. 2010;29:1037-57.
49. Miller T, Golemboski K, Ha R, Bunn T, Sanders F, Dietert R. Developmental exposure to lead causes persistent immunotoxicity in Fischer 344 rats. Toxicol Sci. 1998;42:129-35

50. Gao D, Mondal TK, Lawrence D. a. Lead effects on development and function of bone marrow-derived dendritic cells promote Th2 immune responses. Toxicol Appl Pharmacol. 2007;222:69-79.

51. Jedrychowski W, Perera F, Maugeri U, Miller RL, Rembiasz M, Flak E, et al. Intrauterine exposure to lead may enhance sensitization to common inhalant allergens in early childhood: a prospective prebirth cohort study. Environ Res. 2011;111:119-24.

52. Karmaus W, Brooks KR, Nebe T, Witten J, Obi-Osius N, Kruse H. Immune function biomarkers in children exposed to lead and organochlorine compounds: a cross-sectional study. Environ Health. 2005;4(1):5.

53. Lutz PM, Wilson TJ, Ireland J. Jones a L, Gorman JS, Gale NL, et al. Elevated immunoglobulin $\mathrm{E}$ (lgE) levels in children with exposure to environmental lead. Toxicology. 1999;134:63-78.

54. Sun L, Hu J, Li L, Cheng H. Influence of exposure to environmental lead on serum immunoglobulin in preschool children. Environ Res. 2003;92:124-8.

55. Hon K-LE, Wang SS, Hung ECW, Lam HS, Lui HHK, Chow C-M, et al. Serum levels of heavy metals in childhood eczema and skin diseases: friends or foes. Pediatr Allergy Immunol. 2010;21:831-6.

56. Gascon M, Sunyer J, Casas M, Martínez D, Ballester F, Basterrechea M, et al. Prenatal exposure to DDE and PCB 153 and respiratory health in early childhood: A Meta-Analysis. Epidemiology. 2014;25:544-53.

57. Hansen S, Strøm M, Olsen SF, Maslova E, Rantakokko P, Kiviranta H. Maternal Concentrations of Persistent Organochlorine Pollutants and the Risk of Asthma in Offspring : Results from a Prospective Cohort with 20 Years of follow-up. Environ Health Perspect. 2014;122:93-9.

58. Noakes PS, Taylor P, Wilkinson S, Prescott SL. The relationship between persistent organic pollutants in maternal and neonatal tissues and immune responses to allergens: A novel exploratory study. Chemosphere. 2006;63:1304-11.

59. Sunyer J, Garcia-Esteban R, Alvarez M, Guxens M, Goñi F, Basterrechea M, et al. DDE in mothers' blood during pregnancy and lower respiratory tract infections in their infants. Epidemiology. 2010;21:729-35.

60. Health Canada. What is lead. 2013. http://www.hc-sc.gc.ca/ewh-semt/ contaminants/lead-plomb/index-eng.php. Accessed 9 July 2014

61. Liew Z, Olsen J, Cui X, Ritz B, Arah OA. Bias from conditioning on live birth in pregnancy cohorts: an illustration based on neurodevelopment in children after prenatal exposure to organic pollutants. Int J Epidemiol. 2015;44:345-54.

62. Lambert WE, Lasarev M, Muniz J, Scherer J, Rothlein J, Santana J, et al. Variation in Organophosphate Pesticide Metabolites in Urine of Children Living in Agricultural Communities. Environ Health Perspect. 2005;113:504-8.

63. Rauch SA, Braun JM, Barr DB, Calafat AM, Khoury J, Montesano MA. Associations of prenatal exposure to organophosphate pesticide metabolites with gestational age and birth weight. Environ Health Perspect. 2012;120:1055-61.

64. Wacholder S. When measurement errors correlate with truth:suprising effects of nondifferential misclassification. Epidemiology. 1995;6:157-61.

65. Muehleisen B, Gallo RL. Vitamin D in allergic disease: shedding light on a complex problem. J Allergy Clin Immunol. 2013;131:324-9.

66. World Health Organization. 2000. Obesity: preventing and managing the global epidemic. Report of a WHO consulation (WHO Technical Report Series 894). http://www.who.int/nutrition/publications/obesity/ WHO_TRS_894/en/. Accessed 25 March 2015.

\section{Submit your next manuscript to BioMed Central and take full advantage of:}

- Convenient online submission

- Thorough peer review

- No space constraints or color figure charges

- Immediate publication on acceptance

- Inclusion in PubMed, CAS, Scopus and Google Scholar

- Research which is freely available for redistribution 